\title{
Laboratory assessment of inhibition efficiency and mechanism of inhibitor blend (P22SU) on mild steel corrosion in high chloride containing water
}

\author{
A. Shaban, ${ }^{1 *}$ I. Felhosi ${ }^{1}$ and J. Telegdi ${ }^{1,2}$ \\ ${ }^{1}$ Institute of Materials and Environmental Chemistry, Research Centre for Natural \\ Sciences, Hungarian Academy of Sciences, H-1117, Magyar tudósok körútja 2, Bp., \\ Hungary \\ ${ }^{2}$ Óbuda University, Faculty of Light Industry and Environmental Engineering, \\ H-1034, Doberdó u. 6., Bp., Hungary \\ *E-mail: shaban.abdul@ttk.mta.hu
}

\begin{abstract}
The corrosion inhibition process of phosphonic-acid based inhibitor blends (Corin P22SU), on mild steel corrosion in simulated cooling water (SCW) containing chloride ion has been investigated using electrochemical methods (impedance spectroscopy (EIS), open circuit potential (OCP) and visual characterization). The synergistic effect on the inhibition efficiency of the commercially produced (Corin P22SU) inhibitor with different concentrations of nitrite was examined. Inhibition activity increases with the increase of Corin P22SU concentration. The experimental parameters were concentration of the inhibitor, and soaking time. P22SU inhibits mild steel corrosion in near neutral and alkaline $(\mathrm{pH} \geq 6) \mathrm{SCW}$. Inhibitive action was increased with the increase of soaking time up to six hours and afterwards. Based on the experimental results, mechanisms of action of Corin P22SU on mild steel corrosion inhibition in SCW have been proposed.
\end{abstract}

Keywords: steel corrosion, corrosion inhibition, sodium nitrite, passive film, electrochemical impedance spectra (EIS).

Received: March 27, 2017. Published: June 17, 2017.

doi: $\underline{10.17675 / 2305-6894-2017-6-3-3}$

\section{Introduction}

Although many methods have been employed to prevent the corrosion of steel but the use of inhibitor is the most convenient and economic method in liquid containing system such as in boiler, condenser, heat exchanger, pipe lines, petroleum industries and other chemical process industries [1-3]. Due to stricter environmental regulations, the applications of hazardous and toxic chromate based inhibitors in open industrial systems have been restricted or banned [4-8]. Therefore, attention was focused on the development of substitute nontoxic alternatives to inorganic inhibitors applied earlier.

Passivating inhibitors are the most efficient inhibitors used in cooling water systems $[9,10]$. Passivators, which noticeably shift the potential of a metal to a more noble 
(positive) value by a virtue of forming a protective oxide film on the metal anodic sites, are widely used because of its effectiveness on corrosion of steels and other alloy systems, compared to other types of inhibitors [1,9-11]. However, in general, passivating inhibitors can actually cause pitting and accelerate corrosion when concentrations fall below minimum limits $[1,9]$. For this reason, passivators must be applied with caution.

Synergism, which implies applying multicomponent inhibitor mixtures, can play a big role in developing more efficient, less toxic chemicals and at lower concentrations blend as corrosion inhibitors with optimal anticorrosion effect [12]. Corin P22SU is a blend of corrosion and scale inhibitors, which contains some organic acids (potassium salt of hydroxy-ethane-diphosphonic acid (HEDP)), inorganic additives, and potassium phosphates. The inhibition effect is based on the synergistic effect of the inorganic and organic components and on the film forming capability.

The aim of this study is to investigate the inhibition effect of Corin P22SU inhibitor against carbon steel corrosion in chloride containing model solution. The inhibition effect will be followed for 3 days of immersion time by electrochemical impedance spectroscopy (EIS). Furthermore, information on the mechanism of inhibitory action was obtained from EIS spectra.

\section{Experimental procedures}

Electrochemical experiments were performed using a three-electrode cell of $500 \mathrm{~cm}^{3}$ volume at room temperature. The working electrode was carbon steel embedded into epoxy resin, the counter electrode was platinum net, and reference electrode was a saturated calomel electrode (SCE).

\subsection{Electrolytes}

Simulated cooling water (SCW) compositions were used as electrolytes and were prepared as shown in Table 1. Concentration of the inhibitor: 1000, 2000 and 3000 ppm.

\subsection{Electrode material}

Carbon steel electrode: A38 (Fe235B, according to MSZ-500-1989): C: 0.17\%, P: 0.045\%, S: $0.045 \%, \mathrm{~N}: 0.009 \%$, Fe: balance.

Table 1. Composition of the simulated water (to $1 \mathrm{~L}$ of distilled water).

\begin{tabular}{ccccc}
\hline Chemical added & $\begin{array}{c}\text { Weight } \\
(\mathbf{m g} / \mathbf{l})\end{array}$ & & Anion & $\begin{array}{c}\text { Concentration } \\
\text { (ppm) }\end{array}$ \\
\hline $\mathrm{NaCl}$ & 524 & $\rightarrow$ & $\mathrm{Cl}^{-}$ & 318 \\
$\mathrm{CaSO}_{2} \cdot 2 \mathrm{H}_{2} \mathrm{O}$ & 503 & $\rightarrow$ & $\mathrm{Ca}^{2+}$ & 117 \\
$\mathrm{MgSO}_{4} \cdot \mathrm{H}_{2} \mathrm{O}$ & 322 & $\rightarrow$ & $\mathrm{Mg}^{2+}$ & 56 \\
\hline
\end{tabular}




\subsection{OCP and EIS measurements}

The protective effect of different inhibitor concentrations was followed by measuring the OCP and the EIS spectra in time. The WE electrode was wet-polished with SiC papers (grit sizes of 800 and 1200), rinsed with acetone and double distilled water, then immersed in the electrolyte solution. Measurements were performed at room temperature according to the procedure described in ASTM G5-14 standard [13, 14].

EIS tests were carried out using Solartron 1286 Potentiostat and 1250 FRA. A potential sine wave with $10 \mathrm{mV}$ amplitude was used to perturb the system with long autointegration, measuring 10 points/decade. The applied frequency range (time necessary to measure the impedance spectra) was previously optimized according to the change of OCP in time. Different frequency ranges were used (from $10 \mathrm{kHz}$ to $10 \mathrm{mHz}$; from $10 \mathrm{kHz}$ to $2 \mathrm{mHz}$; or $10 \mathrm{kHz}$ to $1 \mathrm{mHz}$ ) depending on the speed of the shift of open circuit potential, and shape of impedance spectra. Namely: If the open circuit potential is shifting faster, shorter frequency range may be used, since the difference between the open circuit potential and bias should not be larger than the amplitude of the inlet potential signal during the whole measurement time. Otherwise the impedance spectra are corresponding not to the free corrosion but to the polarized dissolution.

Impedance spectra were measured in time with batch mode in order to monitor the change of inhibitor effect in time for 3 days:

- Open circuit potential was measured during the first hour of immersion, and the first impedance spectrum was measured after it between the frequency range of $10 \mathrm{kHz}-10 \mathrm{mHz}$.

- The second impedance spectrum was recorded after 2 hours of immersion.

- Further, minimum $90 \mathrm{~min}$ waiting time was applied between measurements of impedance spectra.

The quantitative analysis of the experimental impedance data was performed by the non-linear least square minimization method using a theoretical transfer function.

The polarization curves in uninhibited and inhibitor-containing solutions have been detected after $1 \mathrm{~h}$ of immersion time with a sweep rate of $10 \mathrm{mV} / \mathrm{min}$ using Solartron 1286 Potentiostat. Anodic and cathodic curves have been measured separately; starting the measurement from the open circuit potential to $+500 \mathrm{mV}$ or to $-1400 \mathrm{mV}$, respectively. No IR compensation has been used during the measurements.

Images of the electrodes were made in order to visualize the corrosion and inhibition effects.

\section{Results and Discussion}

\subsection{Effectiveness of Corin P22SU.}

The inhibition efficiency of Corin P22SU inhibitor has been investigated in three different concentrations: 1000, 2000, and $3000 \mathrm{ppm}$. 
The change of corrosion potential of steel in time during the first hour of immersion is presented in Figure 1. It is seen that after a short transition time $(5-10 \mathrm{~min})$ the corrosion potential is increasing, indicating the protective anodic inhibitor film formation. In all concentrations, the corrosion potential is larger than that of the blank (inhibitor free) solution. The tendency of the change of potential (continuous shift of potential from active to pre-passive potential range) in solutions containing $2000 \mathrm{ppm}$ or $3000 \mathrm{ppm}$ inhibitor indicate the good quality of the formed inhibitor film.

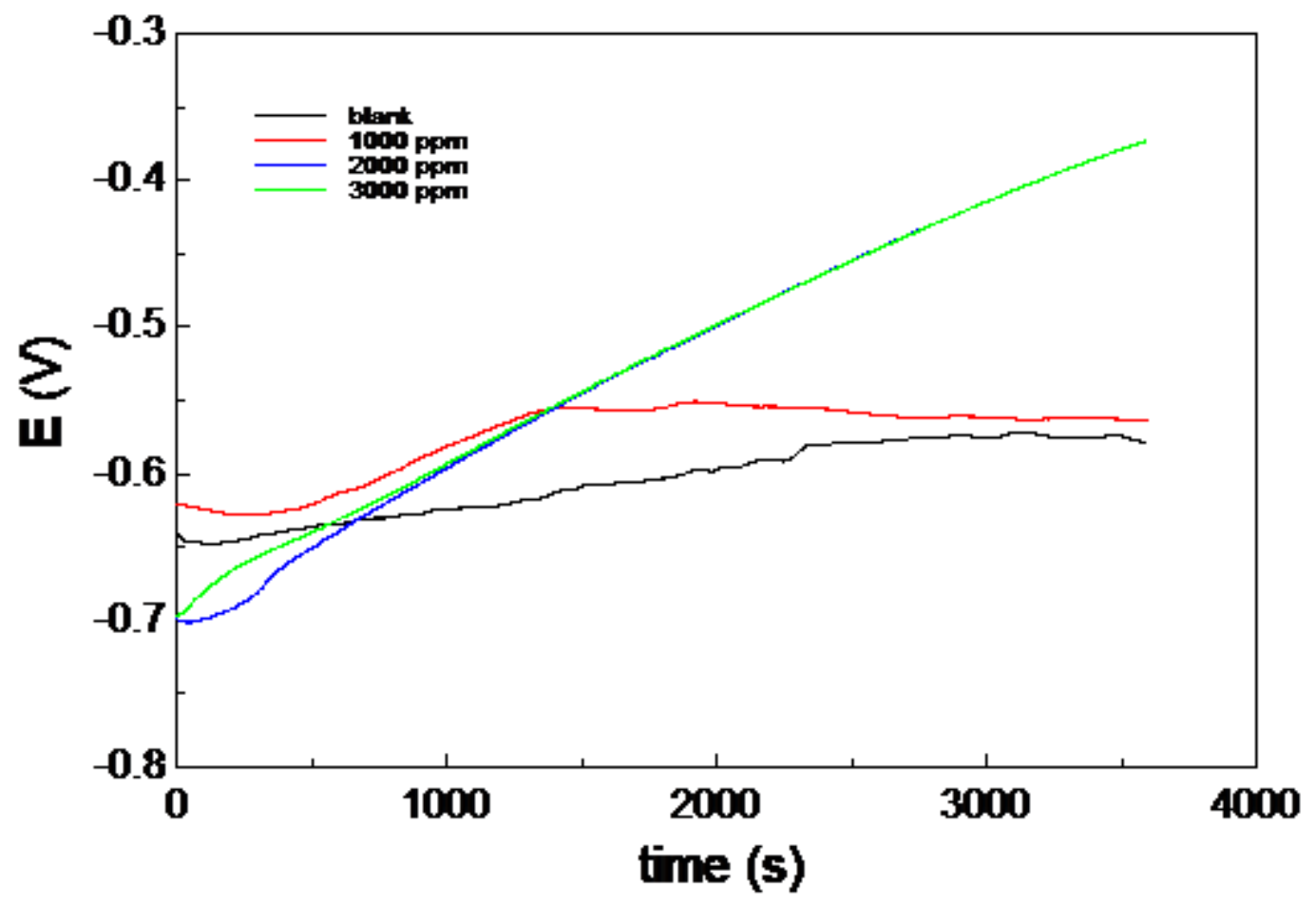

Figure 1. Change of corrosion potential of steel in SCW with and without Corin P22SU inhibitor at different concentration during the first hour of immersion.

The change of corrosion potential in time and difference of corrosion potential of steel in inhibited and uninhibited solutions give good indication on the inhibition effect of inhibitors. Usually, applying anodic inhibitors, the higher the shift of corrosion potential to anodic direction, the higher the inhibition efficiency may be estimated. (This relationship between corrosion potential and inhibitor efficiency may not be applied to mixed type inhibitors).

The long-term change of corrosion potential of steel in inhibited and uninhibited solutions during 3 days (measured always before each impedance spectra) is plotted in Figure 2. 


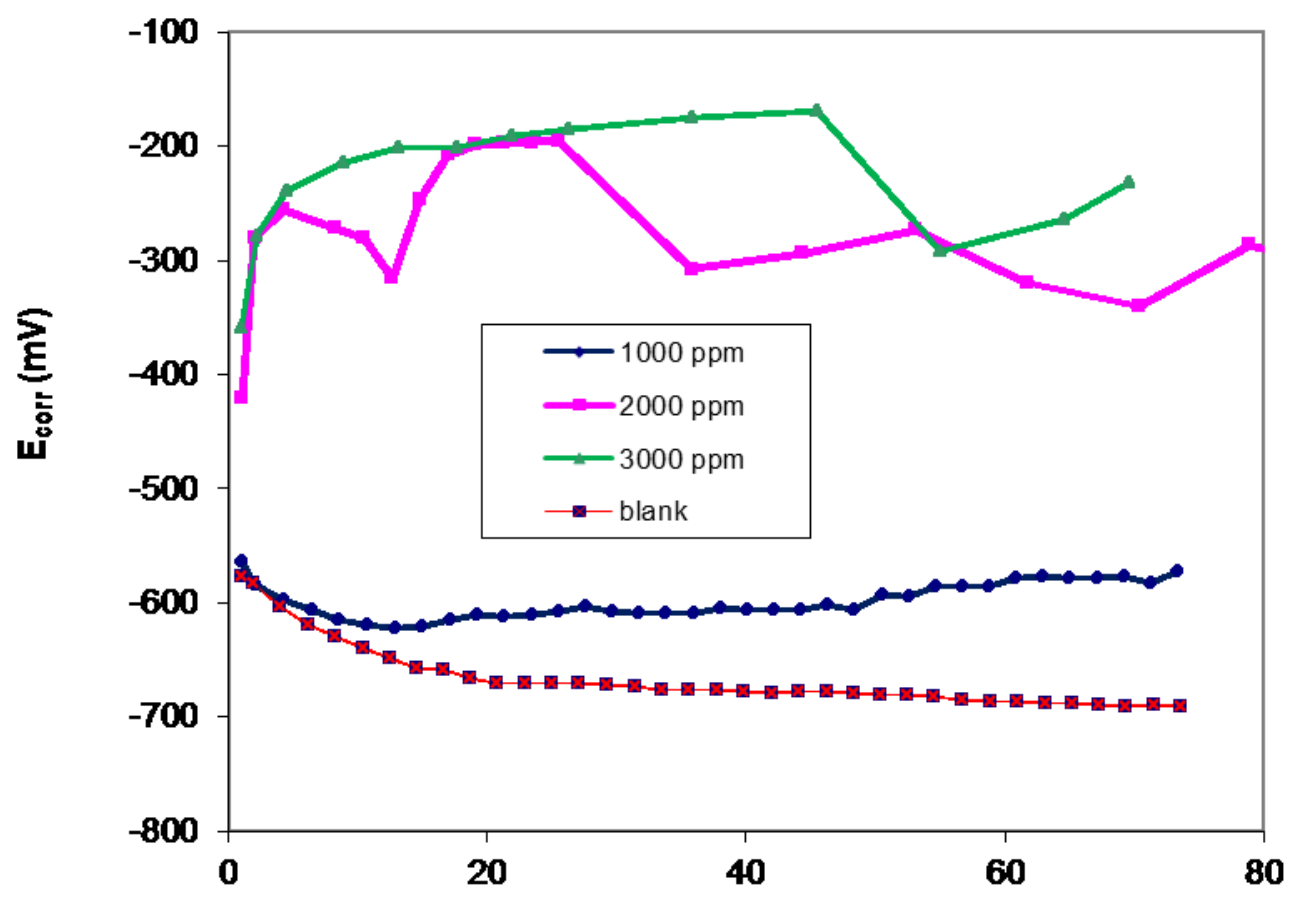

Trme (h)

Figure 2. Change of corrosion potential of steel in SCW with and without Corin P22SU inhibitor during 3 days of immersion.

The stable corrosion potential, near to $-680 \mathrm{mV}$ indicates that the uninhibited steel is in active metal dissolution state (Figure 3).
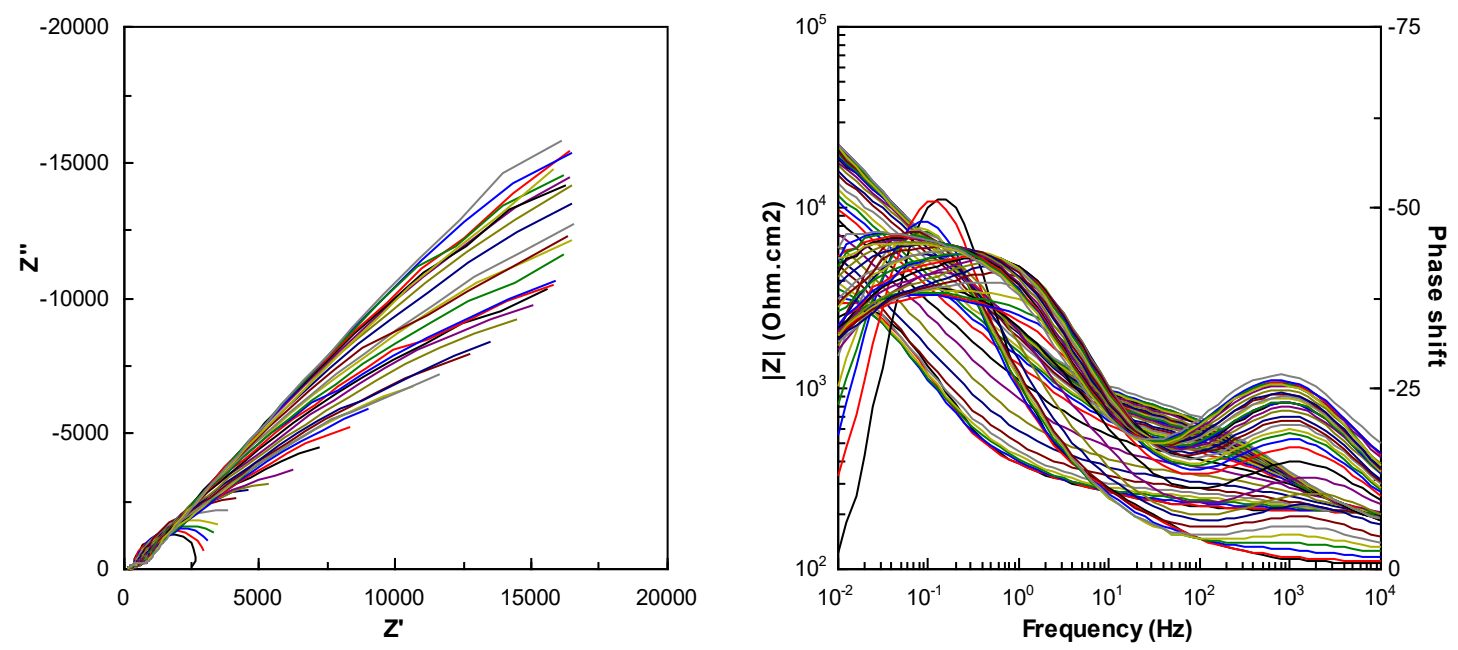

Figure 3. Impedance spectra of carbon steel measured in time in solution of SCW plus 1000 ppm Corin P22SU inhibitor presented in Nyquist and Bode format. 
It is seen that in case of $2000 \mathrm{ppm}$ and $3000 \mathrm{ppm}$ inhibitor concentration the corrosion potential reach $-200 \mathrm{mV}-150 \mathrm{mV}$ values after approx. 20 hours of immersion. This is due to the building of protective layer, and the steel surface has been passivated. Thus the inhibitor layer formation is largely time-dependent, min. 20 hour is necessary to reach good corrosion inhibition of steel.

On the other hand, no passivation of steel is observed in solution containing $1000 \mathrm{ppm}$ inhibitor, although the potential is still larger (more noble) than that of the inhibitor-free solution, indicating that the steel is inhibited in some extent (Figure 2).

Impedance spectroscopy measurements were performed at open circuit potential in time, in order to follow the protective inhibitor layer formation, and numerization the corrosion protection effect. Figure 3 shows a typical impedance spectrum of steel in inhibitor containing solution. The measured spectra were fitted to a general equivalent circuit model which contains the information about the charge transfer process, and protective film properties, too.

The equivalent circuit models used to fit impedance spectra and examples of fitting accuracy have been shown in Figure 4.

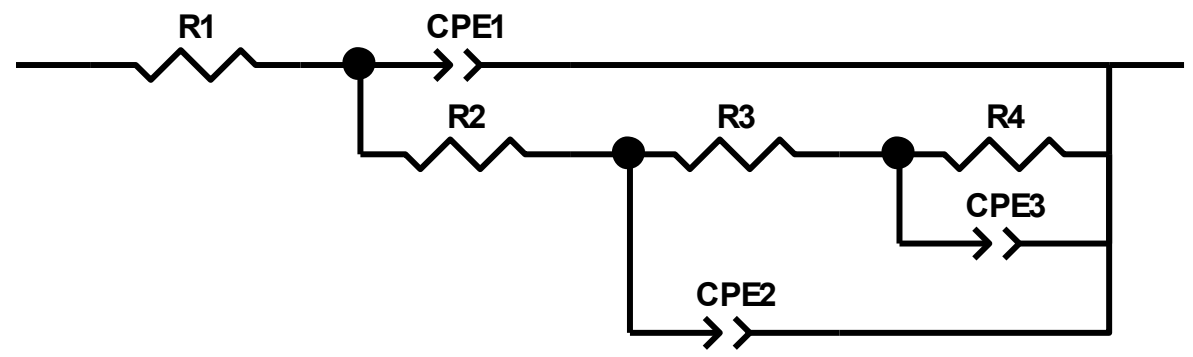

Figure 4. Equivalent circuit model used to fit impedance spectra of carbon steel measured in 1000 ppm Corin P22SU inhibitor solution

The polarization resistance of steel in inhibited and uninhibited solutions has been determined from impedance spectra measured at open circuit potential in all cases. The changes of $R_{\mathrm{p}}$ values during 3 days of immersion are presented in Figure 5.

The polarization resistance of steel in uninhibited model water is reaching a constant value of $1.8 \mathrm{k} \Omega \cdot \mathrm{cm}^{2}$ after 5 hours of immersion (Figure 5), which is generally obtained in near neutral solutions for steel corrosion, independent on the composition of supporting electrolyte and exact composition of mild steel, and determined mostly by the diffusion controlled oxygen reduction. The presence of Corin P22SU inhibitor in all investigated concentrations increased the polarization resistance of steel in the chloride containing model water. Higher the applied inhibitor concentration, higher the polarization resistance is obtained.

In the presence of $1000 \mathrm{ppm}$ inhibitor, continuous increase of polarization resistance is taking place, approaching the value of $100 \mathrm{k} \Omega \cdot \mathrm{cm}^{2}$ during 3 days of immersion time (Figure 5). From the change of $R_{\mathrm{p}}$ we can conclude that the inhibitor film formation at this 
concentration is slow, but the protective effect is evident. The inhibitor efficiency reaches $98 \%$ after 3 days of immersion time.

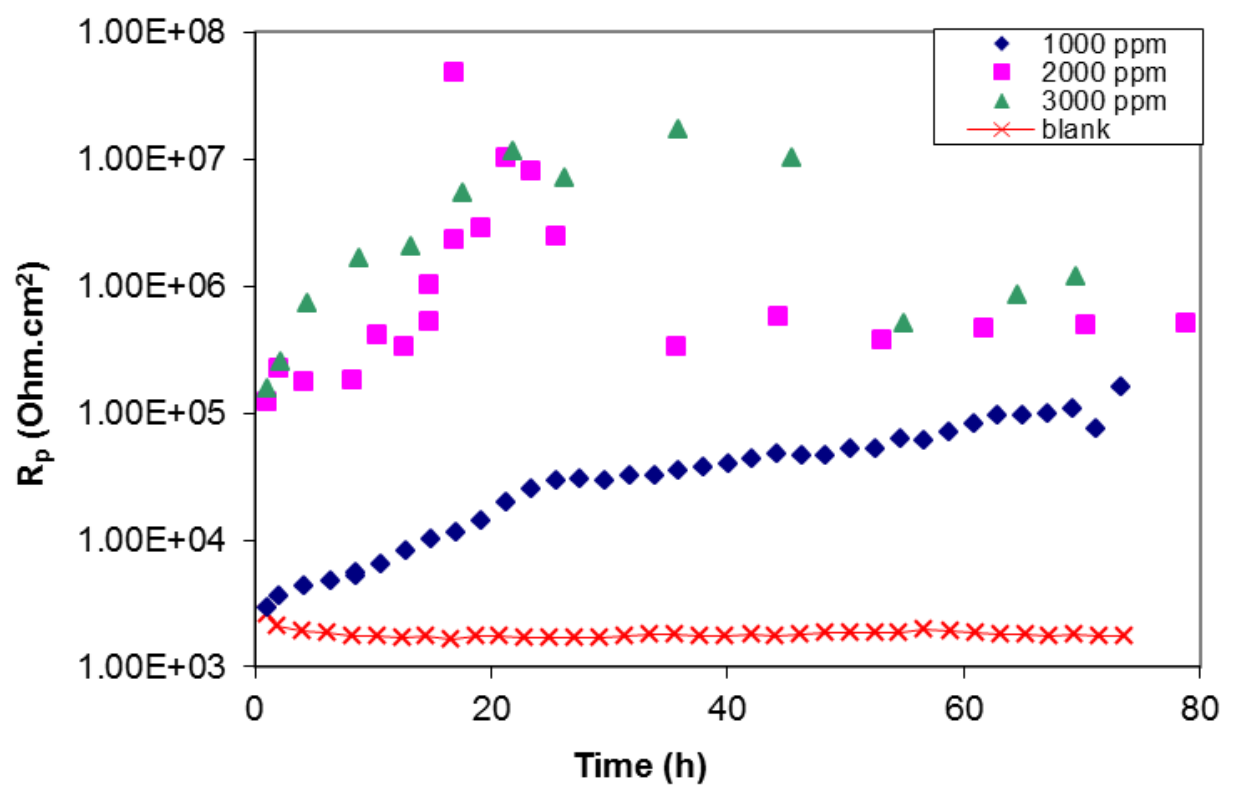

Figure 5. Change of polarization resistance of steel in SCW with and without Corin P22SU inhibitor during 3 days of immersion time $\left(R_{\mathrm{p}}\right.$ values are in logarithmic scale).

Significant increase of polarization resistance was obtained applying higher inhibitor concentration, $2000 \mathrm{ppm}$ and $3000 \mathrm{ppm}$. The $R_{\mathrm{p}}$ is higher than $100 \mathrm{k} \Omega \cdot \mathrm{cm}^{2}$ even after 1 hour of immersion time, and its value is increasing further, approaching the value of $10 \mathrm{M} \Omega \cdot \mathrm{cm}^{2}$ after 1 day of immersion. The inhibitor at these concentrations passivate the steel for one day, parallel, the corrosion potential is reach the value of $-175 \mathrm{mV}$, but this extremely large inhibition is not stable. After one day of immersion decrease in inhibition effect was observed and the polarization resistance decreased to $400-500 \mathrm{k} \Omega \cdot \mathrm{cm}^{2}$, which means that the inhibition efficiency is $99.5 \%$ in the time interval of $1-3$ days (Figures 5 , 6). This decrease in polarization resistance is indicating that in the presence of chloride ions the passive film is not stable, breakdown of protective film is taking place.

Comparing the pictures of steel surface after 3 days of corrosion (Figure 7), it can be found, that the corroded area decreased due to the addition of $1000 \mathrm{ppm}$ inhibitor, but the surface was not protected completely, although the $98 \%$ inhibitor efficiency is large enough, since for most cooling water systems the standard requirement is $95 \%$ protection. The best inhibition was obtained in the case of applying $3000 \mathrm{ppm}$ inhibitor concentration. 


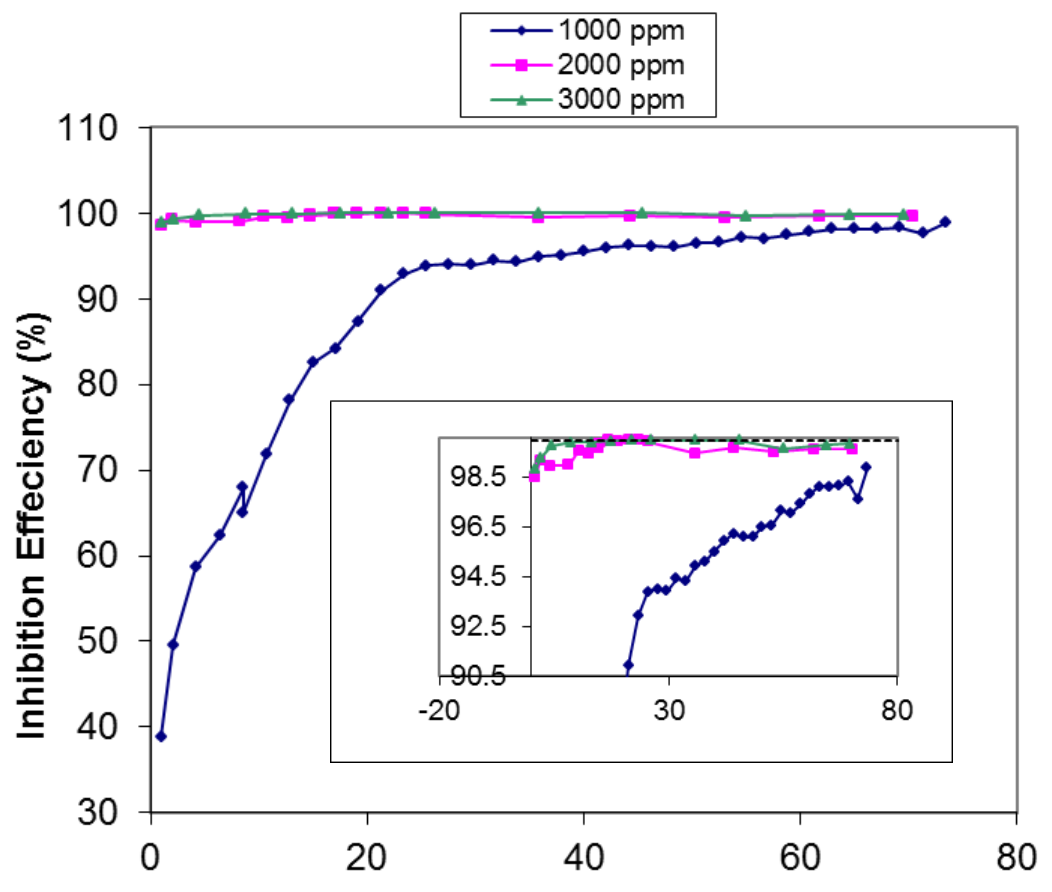

Time (h)

Figure 6. Inhibitor efficiency of Corin P22SU inhibitor at different concentration during 3 days of immersion.

The decrease in inhibition efficiency after one day may be eliminated by continuous dosing of inhibitor into the system or addition of extra passivating agent (such as nitrite) into the solution.

The inhibitor efficiency values has been determined using the following formula:

$$
I E \%=\frac{R_{p(i n h)}-R_{p(o)}}{R_{p(i n h)}} \times 100
$$

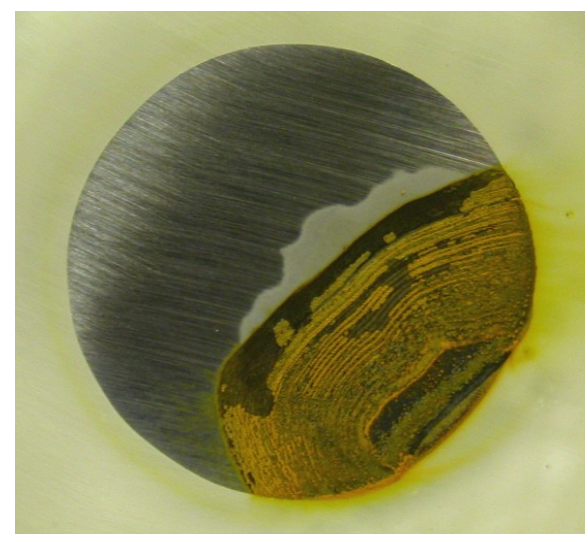

Model water

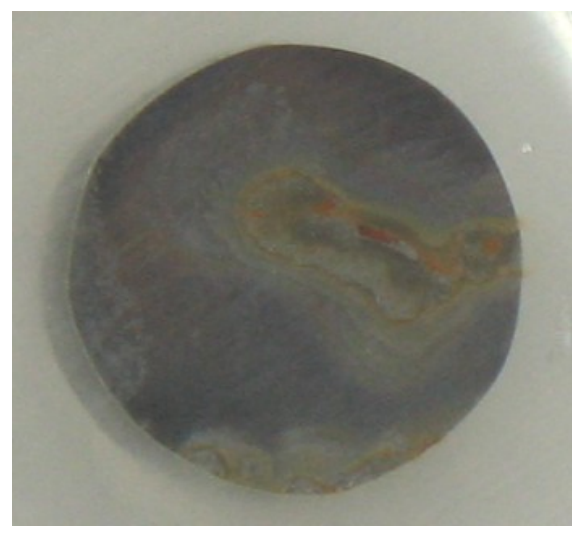

$1000 \mathrm{ppm}$ 


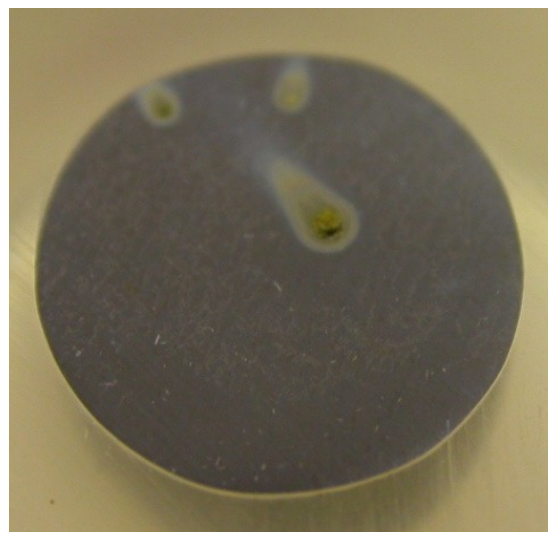

$2000 \mathrm{ppm}$

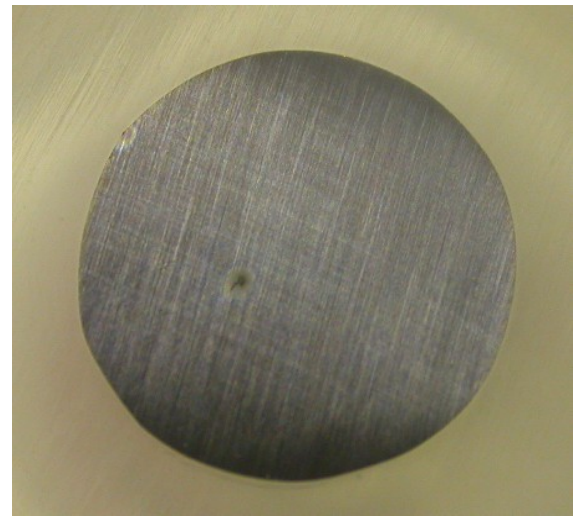

$3000 \mathrm{ppm}$

Figure 7. Pictures of steel surface after 3 days of corrosion in SCW without and with Corin P22SU inhibitor at different concentrations.

\subsection{Mechanism of inhibition}

Information on the mechanism of inhibition may be obtained by recording and comparing the polarization curves of inhibited and uninhibited solutions. It is seen in Figures 8 and 9 that in the presence of inhibitor the corrosion potential shifts to the anodic (more noble) direction, indicating the anodic nature of investigated inhibitor composition.

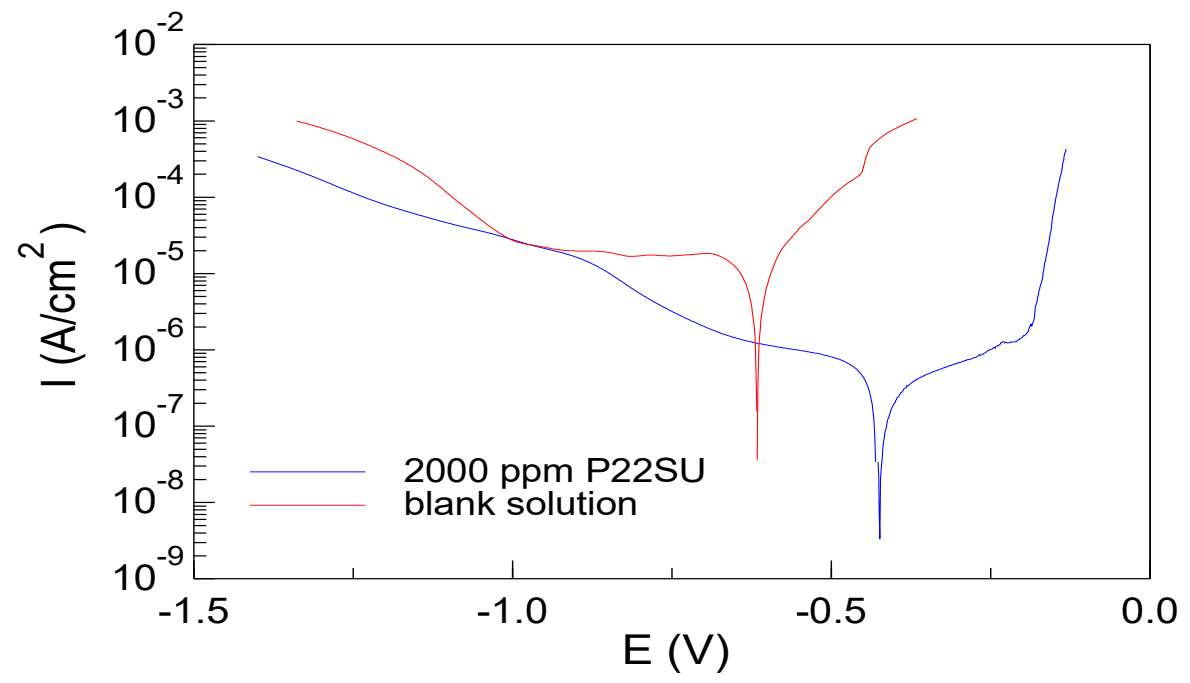

Figure 8. Polarization curves of steel in SCW with and without $2000 \mathrm{ppm}$ P22SU corrosion inhibitor, sweep rate: $10 \mathrm{mV} / \mathrm{min}$, measured after $1 \mathrm{~h}$ of immersion time. 

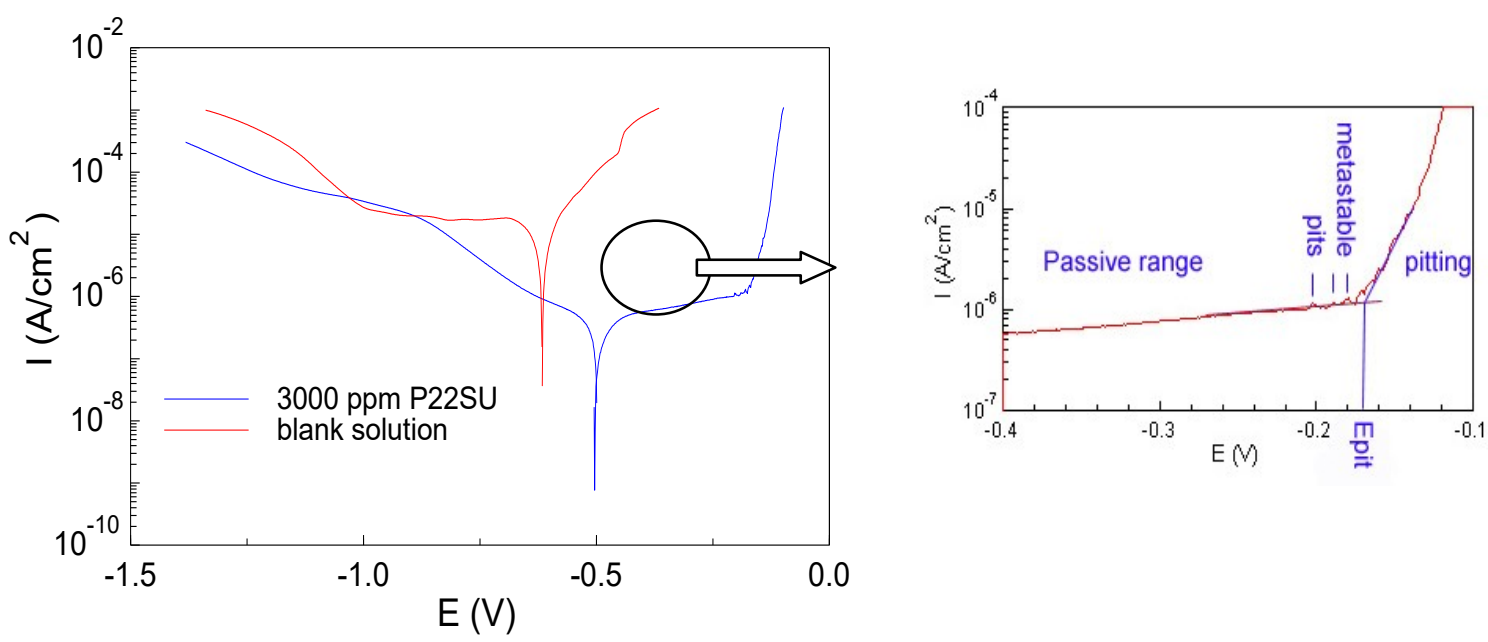

Figure 9. Polarization curves of steel in SCW with and without $3000 \mathrm{ppm}$ P22SU corrosion inhibitor, sweep rate: $10 \mathrm{mV} / \mathrm{min}$, measured after $30 \mathrm{~min}$ of immersion time.

In the uninhibited solutions, the following electrochemical reactions are taking place:

$$
\begin{aligned}
& \text { anodic iron dissolution: } \mathrm{Fe} \rightarrow \mathrm{Fe}^{2+}+2 \mathrm{e}^{-} \\
& \text {cathodic oxygen reduction: } \mathrm{O}_{2}+2 \mathrm{H}_{2} \mathrm{O}+4 \mathrm{e}^{-} \rightarrow 4 \mathrm{OH}^{-} \\
& \text {and cathodic hydrogen evolution: } 2 \mathrm{H}_{2} \mathrm{O}+2 \mathrm{e}^{-} \rightarrow \mathrm{H}_{2}+2 \mathrm{OH}^{-}
\end{aligned}
$$

The polarization curve measured in uninhibited solution shows that the anodic halfreaction (iron dissolution) is charge transfer controlled process. The cathodic part of polarization curve is composed of two electrochemical reactions. The oxygen reduction is diffusion controlled reaction (determining the polarization curve between the potentials of -0.616 to $-1 \mathrm{~V}$ ), while the hydrogen evolution, which is taking place at potentials lower than $-1 \mathrm{~V}$, is charge transfer controlled process.

The presence of inhibitor influences the kinetics of all electrochemical reactions: the iron dissolution, the oxygen reaction and the hydrogen evolution, too. The corrosion inhibition is under mixed control, with more pronounced anodic effect.

The oxygen reduction is also decreased due to the inhibitor, and is not diffusion controlled anymore near to the open circuit potential. This means that most likely the inhibitor influences the charge transfer process of oxygen reduction itself, and not only the oxygen diffusion by forming a diffusion barrier layer.

The hydrogen evolution process was blocked by the inhibitor; the current densities are lower in inhibited solutions than that of the uninhibited solution at potentials lower than $-1 \mathrm{~V}$.

The largest effect may be seen on the anodic reaction, the iron dissolution is decreased significantly due to the inhibitor addition. This indicates the formation of goodquality inhibitor film, which blocks the active sites of metal surface in a large extent. 
Furthermore, the Tafel-slope is increasing in the presence of inhibitor, suggesting that a passive-type layer has been formed on the metal surface.

It is to be mentioned that at a given anodic potential, at a so-called pitting potential breakdown of protective layer is taking place due to the large anodic polarization. This characteristic potential indicates that pitting type corrosion starts at this and larger potentials. The resistance against pitting may be characterized by the difference between the corrosion potential $\left(E_{\text {corr }}\right)$ and pitting potential $\left(E_{\text {pit }}\right)$. Larger the difference, more resistant against the pitting is the metal.

The corrosion potential of steel in inhibitor containing solution is increasing in time as shown in Figure 10, thus the difference between the corrosion potential and pitting potential is decreasing in time. Although the polarization resistance (Figure 11) and inhibition efficiency is increasing as the inhibitor film formation is completing in time, the shift of corrosion potential to the anodic direction due to the formation of anodic type inhibitor film may cause increased risk of localised corrosion. This is why after 2 days of immersion time, reaching the corrosion potential the value of $-175 \mathrm{mV}$, some decrease in protection effect was obtained.

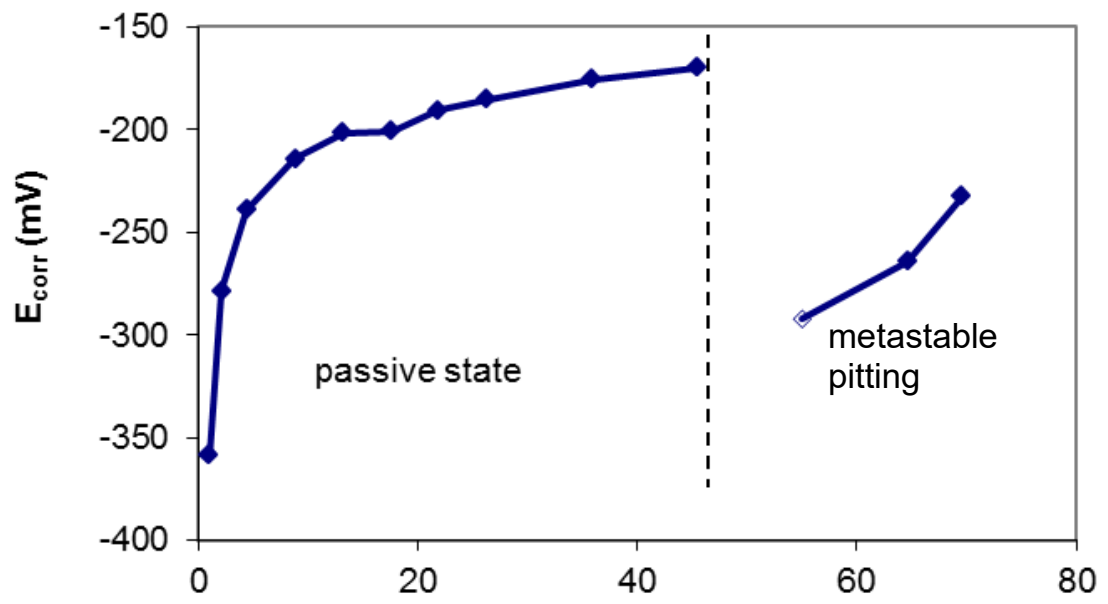

Time (h)

Figure 10. Change of open circuit potential of steel in SCW in the presence of $3000 \mathrm{ppm}$ Corin P22SN inhibitor. 


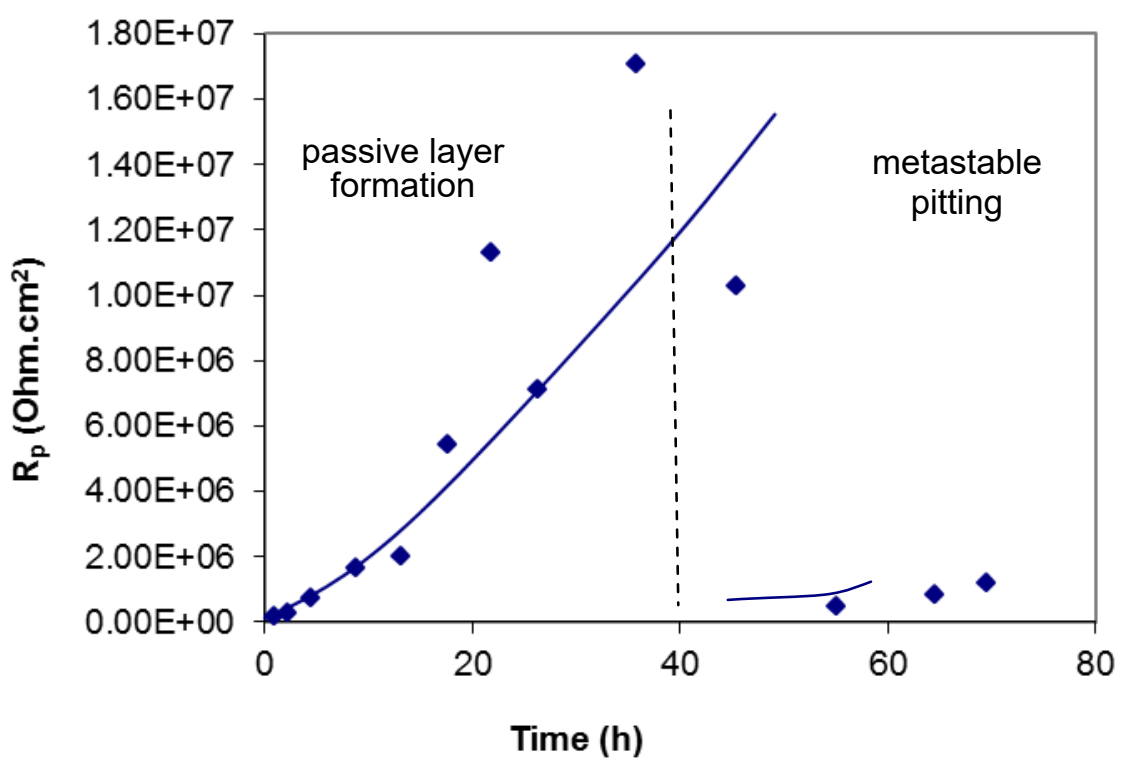

Figure 11. Change of polarization resistance of steel in SCW in the presence of $3000 \mathrm{ppm}$ Corin P22SU inhibitor.

Table 2. OCP, pitting potential, corrosion current density, Tafel parameters and calculated $I E$ from polarization tests of inhibitor-containing SCW (a: anodic, c: cathodic curves).

\begin{tabular}{cccccccc}
$\begin{array}{c}\text { Inhibitor } \\
\text { concentration }\end{array}$ & Time & $\boldsymbol{E}_{\text {corr }}(\mathbf{m V})$ & $\boldsymbol{I}_{\mathbf{c o r r}}\left(\mathbf{A} / \mathbf{c m}^{2}\right)$ & $\boldsymbol{b}_{\mathbf{a}}(\mathbf{m V})$ & $\boldsymbol{b}_{\mathbf{c}}(\mathbf{m V})$ & $\boldsymbol{I E}(\mathbf{\%})$ & $\boldsymbol{E}_{\text {pit }}(\mathbf{m V})$ \\
\hline \multirow{2}{*}{ Blank } & $1 \mathrm{~h} \mathrm{(a)}$ & -615 & $1.06 \cdot 10^{-5}$ & 119 & & - & -450 \\
& $1 \mathrm{~h}(\mathrm{c})$ & -616 & $1.13 \cdot 10^{-5}$ & & -207 & & \\
\hline \multirow{2}{*}{$2000 \mathrm{ppm}$} & $1 \mathrm{~h} \mathrm{(a)}$ & -424 & $2.87 \cdot 10^{-7}$ & 333 & & \multirow{2}{*}{-195.7} & \\
& $1 \mathrm{~h}(\mathrm{c})$ & -430 & $6.54 \cdot 10^{-7}$ & & -680 & & \\
\hline \multirow{2}{*}{$3000 \mathrm{ppm}$} & $30 \mathrm{~min}(\mathrm{a})$ & -504 & $4.06 \cdot 10^{-7}$ & 737 & & \multirow{2}{*}{-175} \\
& $30 \mathrm{~min}(\mathrm{c})$ & -500 & $3.79 \cdot 10^{-7}$ & & -302 & & \\
\hline
\end{tabular}

This is a usual behaviour of anodic type inhibitors, therefore continuous dosing, or monitoring of inhibitor concentration is often applied in water circulations. This effect may be also eliminated by adding another inhibitor component such as nitrite to the system.

The inhibitor efficiency has been calculated by the following formula average of the corrosion current densities calculated from anodic and cathodic fit were taken into account):

$$
I E \%=\frac{i_{\text {corr }(o)}-i_{\text {corr }(i n h)}}{i_{\text {corr }(o)}} \times 100 \%
$$




\section{Conclusions}

The results have shown that Corin P22SU inhibitor is an efficient inhibitor of steel in high chloride containing solutions. The inhibitor efficiency is largely depending on the inhibitor concentration. The inhibitor film formation is time dependent, at least 1 day of immersion time is necessary to reach the optimal protection of steel under the experimental applied in our investigations. The inhibition is under mixed control with more pronounced anodic effect.

Due to the anodic type of inhibition, risk of localised corrosion may occur, which is a usual problem. Care should be taken by controlling the inhibitor concentration or by the addition of synergistic components of cathodic type in order to eliminate this risk.

\section{References}

1. P.R. Roberge, Handbook of Corrosion Engineering, McGraw-Hill, USA, 2000.

2. R.M. Palou, O. Olivares-Xomelt and N.V. Likhanova, Environmentally Friendly Corrosion Inhibitors, in: Developments in Corrosion Protection, Ed. Dr. M. Aliofkhazraei, Ch. 19, InTech, 2014, pp. 431-465. doi: $\underline{10.5772 / 57252}$

3. Yu.I. Kuznetsov, "Progress in the science of corrosion inhibitors," Int. J. Corros. Scale Inhib., 2015, 4, no. 1, 15. doi: 10.17675/2305-6894-2015-4-1-015-034

4. A. El Bribri, M. Tabyaoui, B. Tabyaoui, H. El Attari and F. Bentiss, "The use of Euphorbia falcata extract as eco-friendly corrosion inhibitor of carbon steel in hydrochloric acid solution," Mater. Chem. Phys., 2013, 141, no. 1, 240.

5. B.E. Amitha Rani, B. Bai and J. Basu, "Green Inhibitors for Corrosion Protection of Metals and Alloys: An Overview," Int. J. Corros., Vol. 2012 (2012), Article ID 380217, 15 pp. doi: 10.1155/2012/380217

6. B.N. Popov, Corrosion Inhibitors, In: Corrosion Engineering: Principles and Solved Problems, Ch. 14, Elsevier, 2015, pp. 581-597. doi: 10.1016/B978-0-444-627223.00014-8

7. N. Patni, S. Agarwal and P. Shah, "Greener approach towards corrosion inhibition," Chin. J. Eng., Vol. 2013 (2013), 10 pp. doi: 10.1155/2013/784186

8. Yu.I. Kuznetsov, "Organic corrosion inhibitors: where are we now? A review. Part I. Adsorption," Int. J. Corros. Scale Inhib., 2015, 4, no. 4, 284. doi: 10.17675/23056894-2015-4-4-1

9. I.L. Rozenfeld, Corrosion Inhibitors, McGraw-Hill, New York, 1981.

10. C.G. Dariva and A.F. Galio, Corrosion Inhibitors - Principles, Mechanisms and Applications, in: Developments in Corrosion Protection, Ed. M. Aliofkhazraei, Ch. 16, InTech, 2014, pp. 365-379. doi: 10.5772/57255

11. V.I. Vigdorovich, L.E. Tsygankova, N.V. Loktionov and N.V. Shel, "Passivation of carbon steel in neutral chloride media by inhibited compositions based on normal alkanes," Int. J. Corros. Scale Inhib., 2013, 2, no. 2, 115. doi: 10.17675/2305-68942013-2-2-115-121 
12. T. Trinh Anh, P. Nadine, H. To Thi Xuan, H. Yves and B. Bernard, "Study of the synergistic effect observed for the corrosion protection of a carbon steel by an association of phosphates," Corros. Sci., 2002, 44, 2055. doi: 10.1016/S0010938X(02)00013-6

13. ASTM G5-14, Standard Reference Test Method for Making Potentiodynamic Anodic Polarization Measurements, ASTM International, West Conshohocken, PA, 2014.

14. E.E. Stansbury and R.A. Buchanan, Fundamentals of Electrochemical Corrosion, ASM International, Ohio, USA, 2000, pp. 271-320. 